\title{
Management-based risk prediction in community-acquired pneumonia by scores and biomarkers
}

Martin Kolditz*, Santiago Ewig ${ }^{\#, ๘}$ and Gert Höffken*

ABSTRACT: Community-acquired pneumonia (CAP) represents a major life-threatening infection, but disease course and outcome is highly variable. Major drivers of prognosis are respiratory failure, sepsis-related organ dysfunction and unstable comorbidities.

Current risk stratification tools have been primarily designed to predict mortality and identify low risk patients potentially suitable for ambulatory management. Detection of patients at high risk for clinical deterioration by current scores remains suboptimal.

Therefore, management-related risk stratification tools designed to predict benefit from early intensified monitoring and treatment strategies in hospitalised CAP are advocated. An approach including early and repeatedly evaluated clinical markers of respiratory failure, sepsis-related organ dysfunction or decompensating comorbidity combined with individual definition of treatment goals is suggested.

Inflammatory biomarkers can add prognostic information. New cardiovascular or stress-related biomarkers like copeptin, midregional proadrenomedullin and cortisol have been repeatedly linked with outcome and disease course in CAP and improved clinical scoring in observational studies. Thus they represent promising tools for individualised risk stratification. A major task in future CAP research will be the evaluation of their additional value in large interventional trials with control groups incorporating strict management guidance by clinical criteria.

KEYWORDS: Acute respiratory failure, biomarkers, community-acquired pneumonia, early intervention, risk group, sepsis

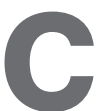
ommunity-acquired pneumonia (CAP) is the number one severe infectious disease in the western world, and disease course and outcome is highly variable. Whereas mortality and complication rates remain low in non-severe CAP managed in the community [1], hospitalised CAP is associated with a high risk of respiratory failure or sepsis-related organ dysfunction. Recent population-based data showed an overall mortality rate of $13 \%$ in hospitalised CAP, rising to more than $35 \%$ in severe CAP [2]. Thus, prognosis resembles that of well-recognised acute emergencies in internal medicine, such as acute myocardial infarction [3], but comparable structured management approaches regarding pre- and early hospital management to improve outcome have not yet been established.

Real life data from Germany illustrate that 39\% of patients receiving mechanical ventilation (and thus dedicated intensive management) do not survive the hospital stay; conversely, only a minority $(16 \%)$ of patients dying in the hospital have been mechanically ventilated [2]. Accordingly, a multicentre database in the USA previously found that only a small proportion of patients experiencing cardiac arrest while hospitalised with pneumonia showed features of severe $\mathrm{CAP}$, such as shock $(33 \%)$ or mechanical ventilation $(36 \%)$, and $38 \%$ of arrests occurred in a normal ward with only $52 \%$ being under cardiorespiratory monitoring [4]. Clinical deterioration, septic organ dysfunction or death predominantly occur within a well-defined time frame of 24-72 $\mathrm{h}$ after hospitalisation [2, 4-6]. For this vulnerable early period, interventions like intensive monitoring and management in the intensive care unit (ICU) [6-8], optimised sepsis management ("sepsis bundles") [9] and early adequate antibiotic therapy $[10,11]$ potentially
AFFILIATIONS

*Division of Pulmonology, Medical Dept 1, University Hospital Carl Gustav Carus, Dresden,

\#Thoraxzentrum Ruhrgebiet, Dept of Respiratory and Infectious Diseases, EVK Herne, Herne, and "Augusta-Kranken-Anstalt Bochum, Bochum, Germany.

\section{CORRESPONDENCE}

M. Kolditz

Dept of Pulmonology

University Hospital Carl Gustav Carus

Fetscherstr. 74

01307 Dresden

Germany

E-mail: martin.kolditz@uniklinikumdresden.de

Received:

July 062012

Accepted after revision:

Sept 172012

First published online:

Sept 272012 
translate into substantial prognosis improvement. However, CAP is a disease of very elderly patients and is frequently considered and managed as a terminal event of severe comorbid conditions. Definition of individual therapeutic goals in this setting is important but little accounted for so far in current guidelines. Additionally, a substantial proportion of CAP mortality is related to unstable or exacerbating pre-existing comorbidities as major risk factors of adverse CAP outcome [2, 12, 13]. A recent prospective study reported acute cardiac events in $27 \%$ of hospitalised CAP patients. Risk was highest within the first $24 \mathrm{~h}$ and cardiac events were associated with poor outcome independent of CAP severity [14]. From these data it seems plausible to argue for routine comorbidity screening and monitoring in early hospitalised CAP. Although the Pneumonia Severity Index (PSI) score implements the presence of comorbidities [13], none of the established risk stratification recommendations accounts for this major prognostic factor in a standardised manner.

Together, these data highlight a gap between current risk stratification approaches and real life situations. The implementation of individualised management-based tools designed to predict benefit from early intensified management and monitoring strategies like early goal directed treatment or monitoring for organ failure is needed.

\section{CLINICAL RISK STRATIFICATION}

\section{Established scores for risk stratification at hospital admission}

International guidelines recommend different clinical scores to support grading of CAP severity. Most established are the PSI score [13], consisting of 20 clinical, laboratory and radiographic variables, and the CRB-65 (confusion, respiratory rate $\geqslant 30 \mathrm{~min}^{-1}$, blood pressure $<90 / \geqslant 60 \mathrm{mmHg}$, age $>65$ years) [1] and the CURB score (urea $>7 \mathrm{mmol} \cdot \mathrm{L}^{-1}$ instead of age) [15] criteria, which include only four parameters. The CRB-65 score is the most easy to calculate and thus widely used in Europe $[16,17]$. Both proved to be comparable tools for mortality prediction and identification of low risk patients suitable for ambulatory management, and mortality in low risk patients (PSI score I-III; CURB/CRB-65 score 0) consistently is below $2 \%[1,18,19]$.

For prediction of severe $\mathrm{CAP}$, studies frequently use the clinical surrogate of ICU admission. Here, the 2001 American Thoracic Society (ATS)- [20] and 2007 ATS/Infectious Diseases Society of America (IDSA)-rules [21] indicating features of sepsis-related organ dysfunction or respiratory disturbance performed best and are widely recommended [21-23]. The 2001 rule consists of two major criteria (requirement for mechanical ventilation, presence of septic shock) and three minor criteria (systolic blood pressure $<90 \mathrm{mmHg}$, multilobar infiltrate, arterial oxygen tension/inspiratory oxygen fraction $<250$ ), while the 2007 rule added six more minor criteria (respiratory rate $>30 \mathrm{~min}^{-1}$; confusion; blood urea nitrogen $>20 \mathrm{mg} \cdot \mathrm{dL}^{-1}$; leukopenia; thrombocytopenia; hypothermia). Both have a superior performance to the PSI or CURB scores for prediction of ICU admission (pooled sensitivity of $61-67 \%$, positive likelihood ratio 6.2-7.1) [22]. Other scoring systems, such as the SMART-COP rule [24], the SCAP/Espana rule [25, 26], the CORB score [27] and the REA-ICU rule [28] have been introduced and incorporate variations of the ATS minor criteria and/or additional factors such as low arterial $\mathrm{pH}$, albumin, tachycardia and hyponatraemia. While their prediction of severe CAP showed accuracies comparable to those of the ATS rules [23, 29], the latter three have not been validated in external cohorts so far. A recent study compared most of these scores with a rigorous design, excluding patients with immediate need for vasopressor use and/or mechanical ventilation as well as patients not suitable for ICU care owing to advanced directives or major comorbid illnesses [23]. Evaluated end-points included the need for mechanical ventilation or vasopressor use, and the 2007 minor criteria achieved the highest prediction (area under the curve 0.85: sensitivity $79 \%$, positive predicted value $23 \%$ ).

\section{Problems with current risk scores}

Most studies evaluated prognostic scores by observational design. To prove clinical utility, interventional trials demonstrating improvement of clinical end-points, such as prognosis, treatment failure, treatment allocation, hospital stay or cost, would be required. So far trials proving accurate identification of low risk patients suitable for ambulatory treatment without compromising their safety have been performed only for the PSI score [30-33], and no clinical end-point studies exist for high risk prediction.

Evidence from observational studies suggests that both the CURB/CRB-65 and PSI scores perform more poorly in predicting high risk patients, as they show low positive likelihood ratios at the recommended cut-off points for the prediction of 30-day mortality (PSI $\geqslant 4$ : positive likelihood ratio 1.9 ; CRB-65 $\geqslant 2$ : positive likelihood ratio 2.4) [18, 19]. Moreover, accurate mortality prediction does not always lead to accurate identification of patients developing severe CAP and who are in need of intensified management strategies. As there is no generally accepted definition for severe CAP, the most widely used surrogate for high risk prediction is ICU admission. This end-point is vulnerable to bias by ICU admission policy and highly dependent on individual physician decisions. Treatment restrictions bias this end-point further. In a recent study $35 \%$ (563 out of 1,625) of consecutive patients showed "contraindications" for ICU admission [23]. Both the CRB-65/CURB (pooled sensitivity only 49\%) and PSI scores (pooled specificity only $48 \%$ ) lack accuracy for prediction of ICU admission [22]. Even the 2007 ATS/IDSA rule showed a pooled sensitivity of only $61 \%$ in a recent metaanalysis, meaning that $39 \%$ of patients deteriorating in the course would be missed [22]. Additionally, the two major criteria of the ATS rules rather reflect critical disease by themselves instead of being risk factors for it, and ICU referral for patients presenting with manifest respiratory failure or septic shock is self-evident. Consequently, recent studies used the major criteria as end-points [23-25, 27, 34, 35]. By this approach, the 2007 ATS minor criteria achieved a positive likelihood ratio of 4.3 and a negative likelihood ratio of 0.26 [23], clearly missing the recommended threshold of 10/0.1 for diagnostic instruments [36]. Their sensitivity of $79 \%$ still means that $21 \%$ of patients deteriorating in the course are missed [23]. Moreover, prediction of vasopressor use or mechanical ventilation still represents only a subgroup of patients in need of intensified management strategies for sepsis-related organ 
failure, such as fluid resuscitation responsive hypotension or instable comorbidities. Thus, optimal prediction of severe CAP should primarily aim to identify all patients who benefit from intensified monitoring and management strategies rather than a specific site of care prediction, as recently suggested [29].

\section{Risk of unstable comorbidities}

Pre-existing comorbidities, such as chronic renal, hepatic, cardiac, cerebrovascular and neoplastic disease or diabetes mellitus, have been independently associated with adverse prognosis in CAP $[2,13,14,37-40]$. Acute systemic inflammatory and pro-coagulatory changes caused by CAP increase the risk for decompensation of organ function [14, 38-40]. Nonpulmonary acute organ dysfunction occurs in about $40 \%$ of hospitalised CAP patients and is already present in half of them at hospital admission [41]. For acute cardiac events it has been shown that risk is elevated in patients with pre-existing cardiac disease (OR 4.3) and associated with pneumonia severity $(37 \% / 43 \%$ in PSI class IV $/ \mathrm{V})$; risk is highest during the first $24 \mathrm{~h}$ of hospitalisation [14]. Therefore, the presence of unstable or decompensating comorbidities should be evaluated routinely as a marker of severe CAP requiring intensified monitoring and management.

\section{Risk stratification in elderly patients and patients from nursing homes}

Increasingly CAP has become a disease of elderly and multimorbid patients, and efforts have been made to describe and categorise special aspects of CAP in this patient group [42, 43]. From several recent European studies it has been consistently shown that the main drivers of poor prognosis in nursing home patients are: 1) poor functional status due to severe and often multiple comorbidities; and 2) hidden or open treatment restrictions rather than treatment failure due to inadequate therapy of multiresistant or rare pathogens [12, 44-46]. Thus, routine assessment of functional status, preferentially defined by a validated score like activities of daily living $(\geqslant 14)$ or World Health Organization performance status $(\geqslant 3)$ has been suggested to account for this important patient group more adequately [43,47]. Established risk stratification tools like the CRB-65 and PSI scores work less well in elderly and severely disabled patients, but can be significantly improved by including oxygenation measurement and assessment of functional status [47-50]. A recent population-based study from Germany showed that especially the negative predictive value of the CRB-65 score for mortality in nursing home patients is insufficient as hospital mortality of identified "low risk" patients was still about $20 \%$, but prediction could be improved by the evaluation of functional status ("bedridden") and comorbidities [50].

Therefore, any risk stratification approach should account for the special requirements in this important patient group by including assessment of comorbidities and functional status, as well as the initial definition and continuous review of individual treatment goals.

\section{Risk stratification in the hospital course}

Existing risk scores have been evaluated for admission scoring only. However, there is an obvious need for repeated evaluation of hospitalised patients to account for the risk of deterioration in the course. Risk of clinical deterioration or death is highest within the first $24-72 \mathrm{~h}$ and fades over the following days $[2,4-6]$. In a recent study, patients with delayed ICU transfer showed an increase of positive minor criteria from two at admission to four at the time of ICU transfer, resulting in a significantly elevated mortality (51 versus 20\%) after late referral [6]. Sepsis-related organ dysfunction in about $50 \%$ of patients only develops after hospital admission [41]. Therefore, repeated clinical re-evaluation in hospitalised CAP patients should be performed until clinical improvement with therapy is evident.

After response to treatment, a simple clinical score can evaluate the risk of subsequent clinical deterioration. These clinical stability criteria consist of five parameters: temperature $\leqslant 37.8^{\circ} \mathrm{C}$, heart rate $\leqslant 100 \mathrm{~min}^{-1}$, respiratory rate $\leqslant 24 \mathrm{~min}^{-1}$, systolic blood pressure $\geqslant 90 \mathrm{mmHg}$ and arterial oxygen saturation $\geqslant 90 \%$ on breathing room air [51]. If these criteria are fulfilled, the risk of serious deterioration with ICU admission or in-hospital death decreases to $<1 \%[51,52]$ and risks for mortality or readmission after discharge to $<3 \%$ and $9 \%$, respectively [53]. These criteria also have been successfully used to guide a switch to oral therapy [54], treatment duration [55] and discharge management [53].

\section{Suggested clinical risk stratification approach for CAP in the hospital}

Because of the limitations of current clinical high risk stratification in hospitalised CAP, a management-based approach has been advocated to identify the need for intensified monitoring and treatment strategies rather than ICU admission or mortality [29]. The basis of this approach constitutes the evaluation of critical organ dysfunction as a consequence of respiratory, cardiocirculatory or comorbidity-related deterioration. Therefore, individual clinical recognition of organ dysfunction by the experienced physician appears to be crucial. Such organ dysfunction should be objectively assessed by the presence of parameters incorporated into evaluated risk scores indicating respiratory failure, sepsis-related organ dysfunction or decompensating comorbidities, which need to be integrated within the individual clinical picture indicating the need for intensified management. Screening for unstable comorbidities should be implemented in all patients with either pre-existing comorbidities or high CAP severity. Additionally, the dynamic nature of pneumonia urges repeated re-evaluation of organ function and minor criteria during the first days of hospitalisation. This algorithm must be supplemented by the continuous evaluation of individual treatment goals.

Resulting management decisions in high risk patients should include: 1 ) repeated (e.g. every $4-6 \mathrm{~h}$ ) evaluation of clinical and vital signs and cardiovascular monitoring; 2) application of recommended management for severe sepsis and septic shock, according to sepsis guidelines [9], including fluid resuscitation with early goal directed treatment within the first $6 \mathrm{~h}$ and early (within the first hours) intravenous broad spectrum antibiotic therapy; 3) repeated evaluation of respiratory function by respiratory rate, oxygenation monitoring and/or blood gas analysis to guide oxygen or ventilator assistance; and 4) regular monitoring of organ function by laboratory parameters and urine output. 
Ambulatory management could be considered in patients: 1) not presenting with the above described features of severe CAP; and 2) showing a low mortality risk according to established risk scores; which 3) should be supplemented by functional assessment in comorbid and elderly patients. After clinical response to treatment, documentation of clinical stability criteria should precede hospital discharge. A resulting algorithm is illustrated in figure 1.

\section{BIOMARKERS TO IMPROVE RISK PREDICTION}

With the described limitations of clinical risk stratification in hospitalised CAP in mind, efforts have been undertaken to improve current strategies by including biomarkers, given their theoretical capability to detect underlying mechanisms of CAP progression in a more accurate and timely manner.

\section{Inflammatory biomarkers}

Inflammatory biomarkers like C-reactive protein (CRP) [56, 57], procalcitonin (PCT) [58-60] and cytokines, such as interleukin (IL)- 6 and tumour necrosis factor (TNF)- $\alpha[56,60,61]$ are associated with mortality and disease severity in CAP; however, their predictive accuracy does not allow their use for high risk prediction by themselves. The most established markers PCT and CRP provide additional information to the clinical scores by identifying low risk patients with low admission levels [56-59] and monitoring treatment response using kinetic data [57, 62-65]. Adequate antibiotic therapy and good prognosis has been demonstrated by decreasing CRP levels after 3-4 days
$[57,64,65]$. Persistent or rising CRP at day 3-4 [64, 65] or PCT at day $3[62,63]$ indicates inadequate treatment and poor prognosis. In clinical treatment failure low PCT levels might raise suspicion of a non-infectious cause, like organising pneumonia [66]. Additionally PCT can be used to guide antibiotic treatment duration. Stopping antibiotics on the basis of low PCT levels in the course has been proven to shorten antibiotic treatment without compromising patient safety in a variety of interventional trials and even in an ICU setting [67-69]. Unfortunately, for demonstrating superiority of a biomarker-guided strategy these studies are limited by the absence of rigorous treatment guidance by established clinical criteria in the control group, but they support the prognostic value of kinetic PCT data. Consequently, re-evaluation of inflammatory biomarkers after 3-4 days to validate treatment response or monitor infectious causes of treatment failure in hospitalised patients has been recommended $[17,70]$.

The main advantage of PCT over CRP in CAP lies in its faster kinetics. However, false-negative admission PCT in patients with severe sepsis or even septic shock has been reported [71]. One possible explanation is a delayed PCT rise after septic stimulus, which can cause a diagnostic gap requiring repeated measurements. Although PCT is more specific than CRP for bacterial infections, its accuracy still does not allow individual prediction of aetiology [72]. Another problem of both markers is their poor prediction of high risk patients. For PCT the positive likelihood ratio for mortality has been as low as 1.4-1.5 in recent

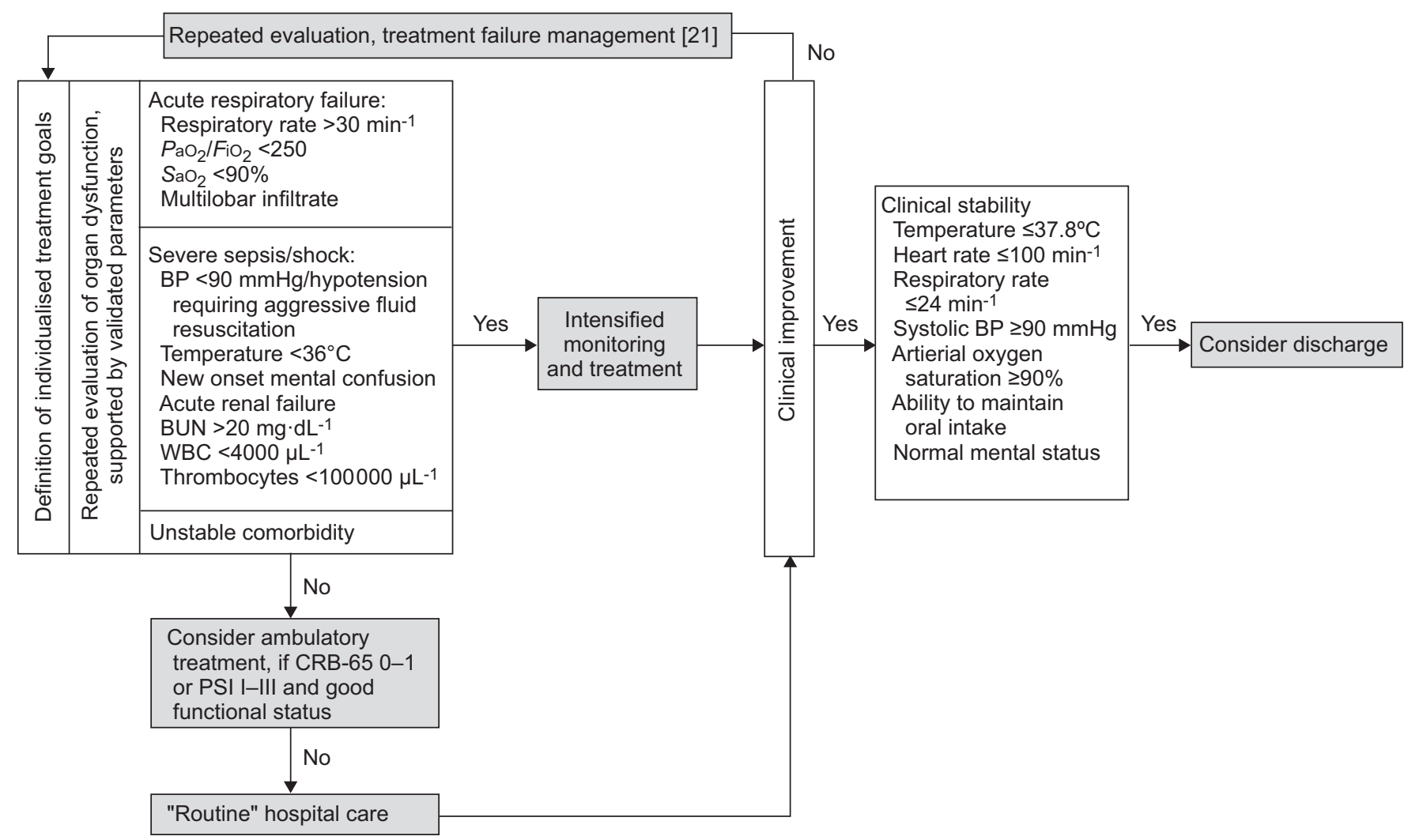

FIGURE 1. Proposed management-based risk stratification algorithm in hospitalised community-acquired pneumonia. $\mathrm{PaO}_{2}$ : arterial oxygen tension; $\mathrm{FiO}_{2}$ : inspiratory oxygen fraction; $\mathrm{SaO}_{2}$ : arterial oxygen saturation; $\mathrm{BP}$ : blood pressure; BUN: blood urea nitrogen; WBC: white blood cell; CRB-65: confusion, respiratory rate $\geqslant 30$ min ${ }^{-1}$, blood pressure $<90 / \geqslant 60 \mathrm{mmHg}$, age $>65$ years; PSI: Pneumonia Severity Index. Modified from [29]. 
large studies $[59,73]$. With these limitations in mind, it is important to emphasise that management decisions primarily have to be driven by clinical criteria, and biomarkers should be evaluated for their additional but not exclusive contribution in guiding management decisions. This has been underlined by a recent interventional study, where the implementation of antibiotic escalation purely based on a PCT-guided protocol lead to antibiotic overtreatment and a worse outcome in ICU patients [74].

\section{Biomarkers reflecting cardiovascular and stress response}

Causes of clinical deterioration in CAP are heterogeneous and include mechanisms reflecting local and systemic inflammation, septic organ dysfunction, underlying or decompensating chronic diseases and stress response. To account for this heterogeneity, it has been emphasised that optimal risk prediction probably should incorporate not only markers reflecting inflammatory status, but also cardiovascular and stress mechanisms of disease progression. From a theoretical point of view it seems attractive to use objective assessment tools of current disease impact to the cardio-circulatory and endogenous stress systems to graduate disease severity and the state of these potential (de)compensating systems.
Accordingly, cardiovascular markers like N-terminal B-type natriuretic peptide (NT-proBNP) [75], proendothelin-1 (proET-1) [76-78], midregional proatrial natriuretic peptide (MR-proANP) [77-79], proarginin-vasopressin (copeptin) [78, 80-84] and midregional proadrenomedullin (MR-proADM) [77, 78, 85-91], coagulatory markers like D-dimer [92, 93] or thrombocytes [94] and markers reflecting stress response like cortisol [61, 95-99] and again copeptin have been repeatedly associated with prognosis in CAP.

The most convincing data accumulated from this evidence currently exists for the markers MR-proADM, copeptin and cortisol. Whereas MR-proADM is a potent vasodilator with immunomodulatory and bactericidal effects, cortisol reflects stress response and immunomodulatory regulation of inflammatory processes and the vasopressin precursor copeptin combines response to stress and fluid balance. Several large, non-interventional studies suggest that these markers improve risk prediction by clinical scores and inflammatory biomarkers. Published results for CAP including used end-points and predictive accuracies are summarised in tables 1-3.

The accuracy of MR-proADM to predict mid- and long-term mortality in CAP repeatedly was superior when compared to
TABLE 1 Studies evaluating
pneumonia (CAP)

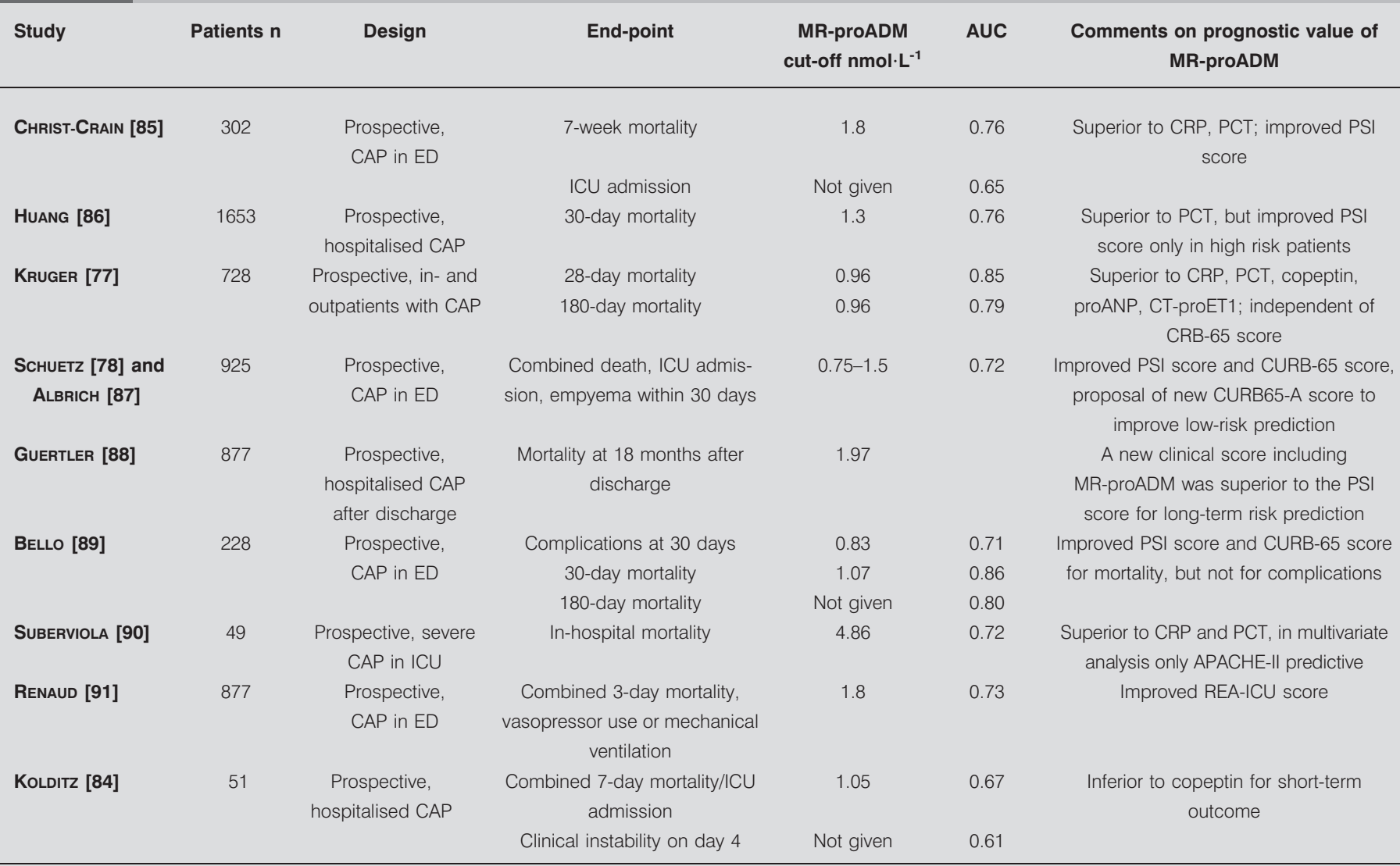

AUC: area under the curve; ED: emergency department; ICU: intensive care unit; CRP: C-reactive protein; PCT: procalcitonin; PSI: Pneumonia Severity Index; proANP: proatrial natriuretic peptide; CT-proET1: C-terminal proendothelin-1; C(U)RB-65: confusion, (urea $>7 \mathrm{mmol} \cdot \mathrm{L}^{-1}$ ) respiratory rate $\geqslant 30 \mathrm{~min}^{-1}$, blood pressure $<90$ / $\geqslant 60 \mathrm{mmHg}$, age $>65$ years. 
TABLE 2 Studies evaluating copeptin as a prognostic parameter in community-acquired pneumonia (CAP)

\begin{tabular}{|c|c|c|c|c|c|c|}
\hline Study & Patients n & Design & End-point & $\begin{array}{l}\text { Copeptin cut-off } \\
\mathrm{pmol} \cdot \mathrm{L}^{-1}\end{array}$ & AUC & $\begin{array}{l}\text { Comments on prognostic value } \\
\text { of copeptin }\end{array}$ \\
\hline $\begin{array}{c}\text { KRUGeR } \\
\text { [81] }\end{array}$ & 589 & $\begin{array}{l}\text { Prospective, in- and } \\
\text { outpatients with CAP }\end{array}$ & 28-day mortality & 29 & 0.86 & $\begin{array}{l}\text { Independent of CRB-65 score, predicted } \\
\text { shock or mechanical ventilation }\end{array}$ \\
\hline $\begin{array}{l}\text { SCHUETZ } \\
\text { [78] }\end{array}$ & 925 & $\begin{array}{l}\text { Prospective, } \\
\text { CAP in ED }\end{array}$ & $\begin{array}{l}\text { Combined death, ICU admission, } \\
\text { empyema within } 30 \text { days }\end{array}$ & 36 & 0.70 & \\
\hline $\begin{array}{c}\text { KRUGER } \\
\text { [79] }\end{array}$ & 1740 & $\begin{array}{l}\text { Prospective, in- and } \\
\text { outpatients with CAP }\end{array}$ & 28-day mortality & 29 & 0.84 & Superior to CRB-65, CRP, PCT \\
\hline $\begin{array}{c}\text { KoLDITZ } \\
{[84]}\end{array}$ & 51 & $\begin{array}{c}\text { Prospective, } \\
\text { hospitalised CAP }\end{array}$ & $\begin{array}{c}\text { Combined 7-day mortality/ICU } \\
\text { admission }\end{array}$ & 35 & 0.81 & $\begin{array}{l}\text { Superior to CRB-65 score, proADM, PCT; } \\
\text { Improved } 2007 \text { ATS/IDSA minor criteria }\end{array}$ \\
\hline
\end{tabular}

AUC: area under the curve; ED: emergency department; PSI: Pneumonia Severity Index; CRP: C-reactive protein; PCT: procalcitonin; CRB-65: confusion, respiratory rate $\geqslant 30 \mathrm{~min}^{-1}$, blood pressure $<90 / \geqslant 60 \mathrm{mmHg}$, age $>65$ years; ICU: intensive care unit; proADM: proadrenomedullin; ATS: American Thoracic Society; IDSA: Infectious Diseases Society of America.

clinical scores or inflammatory and other cardiovascular biomarkers (table 1). One study compared MR-proADM to a large set of biomarkers including CRP, $\mathrm{PCT}$, copeptin, proANP and C-terminal proET1 and found MR-proADM best for prediction of 28- and 180-day mortality [77]. Another group demonstrated its ability to identify patients at risk of poor long term outcome after hospital discharge with CAP [88]. Furthermore, the addition of MR-proADM significantly improved the CURB-65 score to predict a combined end-point of death and pneumonia complications [87]. From this evidence it can be concluded that MR-proADM represents a promising marker to stratify patients according to their mid- and long-term risk for death and complications during and after hospitalisation for CAP. Accordingly, it is currently evaluated as an adjunctive tool in combination with clinical criteria to guide hospital discharge decisions within a first interventional study [87]. Further large interventional trials implementing well-defined clinical discharge criteria in the control group are needed to prove the safety and additional benefit of such a biomarkersupplemented management decision strategy.

Prediction of mortality and complications after 28 or even 180 days might provide identification of low risk patients but it does not reflect an optimal strategy to guide early intensified

TABLE 3 Studies evaluating cortisol as a prognostic parameter in community-acquired pneumonia (CAP)

\begin{tabular}{|c|c|c|c|c|c|c|}
\hline Study & $\begin{array}{c}\text { Patients } \\
n\end{array}$ & Design & End-point & $\begin{array}{l}\text { Cortisol cut-off } \\
\mathrm{nmol} \cdot \mathrm{L}^{-1}\end{array}$ & AUC & $\begin{array}{c}\text { Comments on prognostic value } \\
\text { of cortisol }\end{array}$ \\
\hline Christ-Crain [95] & 251 & $\begin{array}{l}\text { Prospective, } \\
\text { CAP in ED }\end{array}$ & 7-week mortality & 960 & 0.76 & $\begin{array}{l}\text { Independent of PSI score, superior to } \\
\text { CRP, PCT }\end{array}$ \\
\hline Gотон [96] & 64 & $\begin{array}{c}\text { Prospective, } \\
\text { hospitalised CAP }\end{array}$ & Length of hospital stay & 820 & 0.82 & \\
\hline KoLDITZ [61] & 59 & $\begin{array}{l}\text { Prospective, } \\
\text { hospitalised CAP }\end{array}$ & $\begin{array}{l}\text { In-hospital mortality } \\
\text { Clinical instability on day } 4\end{array}$ & $\begin{array}{l}734 \\
571\end{array}$ & $\begin{array}{l}0.83 \\
0.83\end{array}$ & $\begin{array}{l}\text { Independent of PSI score and CRB-65 } \\
\text { score, superior to CRP, PCT }\end{array}$ \\
\hline Remmelts [98] & 270 & $\begin{array}{l}\text { Prospective, } \\
\text { hospitalised CAP }\end{array}$ & $\begin{array}{l}\text { Combined in-hospital } \\
\text { mortality//ICU admission }\end{array}$ & $657-994$ & 0.63 & $\begin{array}{c}\text { Delta cortisol day } 0-2 \text { and } 0-4 \text { with } \\
\text { superior prediction }\end{array}$ \\
\hline KoLDITZ [99] & 984 & $\begin{array}{c}\text { Prospective, } \\
\text { hospitalised CAP }\end{array}$ & $\begin{array}{l}\text { 30-day mortality } \\
\text { Critical CAP }\end{array}$ & $\begin{array}{l}795 \\
795\end{array}$ & $\begin{array}{l}0.70 \\
0.71\end{array}$ & $\begin{array}{l}\text { Improved CRB-65 score, CURB-65 score } \\
\text { and } 2007 \text { ATS/IDSA minor criteria }\end{array}$ \\
\hline
\end{tabular}

AUC: area under the curve; ED: emergency department; PSI: Pneumonia Severity Index; CRP: C-reactive protein; PCT: procalcitonin; ICU: intensive care unit; C(U)RB-65: confusion, (urea $>7 \mathrm{mmol} \cdot \mathrm{L}^{-1}$ ) respiratory rate $\geqslant 30 \mathrm{~min}^{-1}$, blood pressure $<90 / \geqslant 60 \mathrm{mmHg}$, age $>65$ years; ATS: American Thoracic Society; IDSA: Infectious Diseases Society of America. ${ }^{\#}$ : critical CAP: combined death occurring during antibiotic treatment, mechanical ventilation, catecholamine treatment or ICU admission. 
management for patients with clinical deterioration or persistent instability. In a recent large study re-evaluating patients from a prospective trial, MR-proADM identified patients dying or in need of mechanical ventilation/vasopressors within the first 3 days with a sensitivity of $61 \%$ and a specificity of $77 \%$ and significantly improved prediction by one clinical high risk score (REA-ICU) [91]. However, data on prediction of other short term outcomes like ICU admission [85] or clinical deterioration after 7 days and persistent clinical instability [84] by MRproADM have been less convincing, and one small study showed the superior value of copeptin in that setting [84]. More studies including a comparison to the 2007 ATS/IDSA minor criteria and other proposed biomarkers, like copeptin and cortisol, for short term prediction are needed.

In principle, markers of stress like cortisol and copeptin might provide another option for high risk evaluation. Physiologically, acute stress like severe illness leads to an activation of the hypothalamic-pituitary-adrenal axis which protects the organism against excessive inflammatory responses [100]. Studies have shown an increase of cortisol that parallels the severity of infection and prognosis of patients with severe sepsis and septic shock [101]. Copeptin might mirror the individual stress level even more subtly and was found to be associated with disease severity and to discriminate patients with unfavourable outcomes for a variety of conditions [102]. In CAP, copeptin has repeatedly been shown to accurately predict mortality independently of clinical risk prediction by various scores (table 2). The largest study included 1,740 patients and showed the superior accuracy of copeptin for 28-day mortality when compared to the CRB-65 score and the inflammatory biomarkers CRP and PCT. In a recent smaller study, copeptin additionally performed superiorly to PCT and MR-proADM in prediction of clinical instability after $72 \mathrm{~h}$ or early deterioration including death or ICU admission within 1 week and improved clinical prediction by the 2007 minor criteria [84].

Also for cortisol all published studies in CAP demonstrated an association with prognosis independent of clinical risk stratification (table 3). High cortisol levels also predict short term outcomes like persistent clinical instability after $72 \mathrm{~h} \mathrm{[61]} \mathrm{and}$ early disease deterioration defined as death during antibiotic treatment, ICU admission, mechanical ventilation or vasopressor use [99]. For the latter composite end-point, in a study

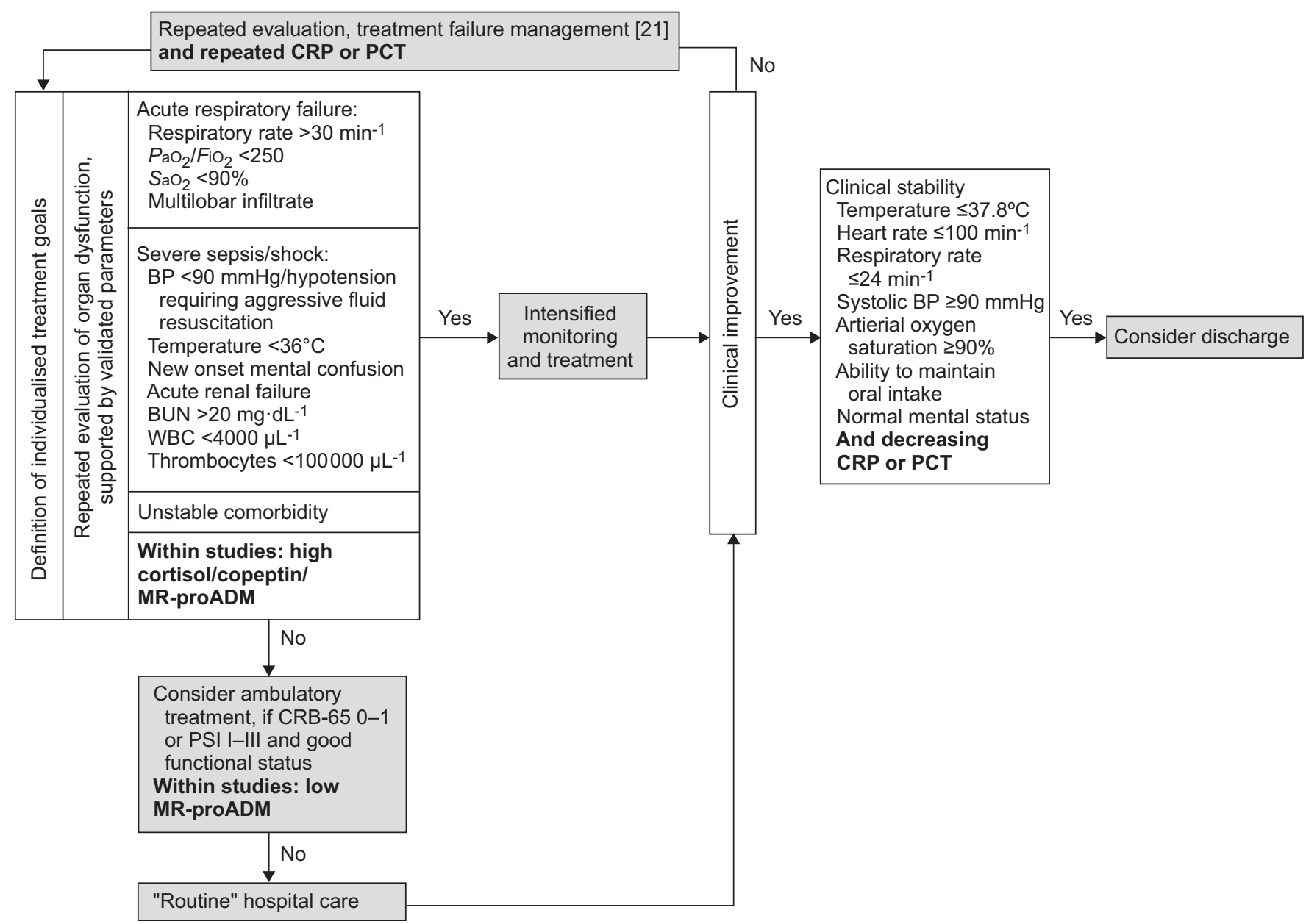

FIGURE 2. Proposed management-based risk stratification algorithm including potential indications for biomarkers in hospitalised community-acquired pneumonia (highlighted in bold type). CRP: C-reactive protein; $\mathrm{PCT}$ : procalcitonin; $\mathrm{PaO}_{2}$ : arterial oxygen tension; $\mathrm{FiO}_{2}$ : inspiratory oxygen fraction; $\mathrm{SaO}_{2}$ : arterial oxygen saturation; $\mathrm{BP}$ : blood pressure; BUN: blood urea nitrogen; WBC: white blood cell; MR-proADM: midregional proadrenomedullin; CRB-65: confusion, respiratory rate $\geqslant 30$ min ${ }^{-1}$, blood pressure $<90 / \geqslant 60 \mathrm{mmHg}$, age $>65$ years; PSI: Pneumonia Severity Index. Modified from [29]. 
including 984 hospitalised CAP patients, cortisol significantly improved the predictive properties of the CRB-65 score and the 2007 minor criteria and was superior to inflammatory biomarkers such as CRP and PCT. Measurement of routinely available total cortisol was at least as good as the more complicated measurement of free cortisol [95]. An unresolved question remains the impact of the blood sampling time point, as cortisol exhibits diurnal concentration changes; however, during infectious diseases this circadian pattern is often lost [103]. Furthermore, its prognostic value certainly would be limited in patients with steroid co-medication.

\section{Strategies to implement biomarkers for risk stratification of CAP in hospital}

Taking these data together, it could be hypothesised that different biomarkers might be used as complementary tools to predict different management decisions in CAP.

The inflammatory biomarkers PCT or CRP have been recommended to validate treatment response in CAP from repeated measurements, with decreasing levels indicating adequate treatment response while persistently elevated or even rising concentrations after 3-4 days of antibiotic treatment together with clinical nonresponse should prompt the evaluation of infectious treatment failure. Very low PCT levels in a patient achieving clinical stability justify the consideration to stop antibiotics.

MR-proADM might be a tool to predict low risk for mortality or complications in patients with a low biomarker concentration. The addition of this marker to clinical scores like the CURB-65 in the future might allow earlier hospital discharge or ambulatory treatment and possibly tailored follow-up concepts, if the first promising study data [87] are confirmed by further trials.

Most work remains to be done for better identification of patients at risk of early clinical deterioration. Here the stress dependent markers copeptin and cortisol are promising candidates for better prognostication, but further comparison to MR-proADM and an optimal combination of minor criteria reflecting respiratory failure and septic organ dysfunction remains to be performed. Also the evaluation and significance of repeated measurements of cardiovascular and stress-dependent biomarkers in this setting are subject to study, as nearly no data exist.

Currently, all these markers are limited by absent rapid or even on-site availability and high costs. Furthermore, any additional benefit of such biomarker complemented strategies over control groups guided by clinical management decision criteria and the optimal combination of biomarkers and clinical scores as well as cut-off points for different clinical settings still have to be confirmed by large interventional trials. Evolving study indications for biomarkers within such concepts are proposed in figure 2. Relevant interventions would include biomarkerguided application of intensified monitoring and management, as well as optimised discharge strategies, and probably further, less defined interventions such as follow-up and secondary prevention measures, or yet to be identified adjuvant treatment options to improve CAP outcome. In the future, such a concept might lead to an individualised stratification and management approach of CAP analogous to the recent progress made in oncology. A first step towards such a scenario is underway in a large German multicentre study, the "Pneumonia Research Network on Genetic Resistance and Susceptibility for the Evolution of Severe Sepsis (PROGRESS)" trial, which is evaluating genomic, transcriptomic and proteomic markers of pneumonia progression to better understand the pathophysiology of CAP progression and derive potential new diagnostic and therapeutic tools to improve the prognosis of this disease.

\section{SUMMARY}

In patients hospitalised for CAP, a management-based risk stratification approach to predict benefit from early intensified monitoring and treatment strategies is advocated. The central tool to rapidly identify patients with severe disease or at risk of deterioration constitutes the early and repeated evaluation of clinical markers for respiratory failure, sepsis-related organ dysfunction or decompensating comorbidity, which should prompt intensified management strategies including close monitoring of organ functions, adequate sepsis management and early intravenous antibiotic therapy. In elderly and severely disabled patients this has to be complemented by the repeated individual definition of treatment goals. Ambulatory management could be considered in patients without features of severe CAP and presenting with a low mortality risk according to established risk scores, which should be supplemented by functional assessment in comorbid and elderly patients. Inflammatory biomarkers, such as CRP and PCT, supplement clinical criteria for monitoring treatment response by follow-up measurements. New cardiovascular or stress-related biomarkers like copeptin, MR-proADM and cortisol represent promising tools for further individualised risk stratification by possibly identifying and validating clinical prognostication of low and high risk patients in the future. A major task in CAP research will be the evaluation of their additional value in large interventional trials with control groups incorporating strict management guidance by clinical criteria.

\section{STATEMENT OF INTEREST}

Conflict of interest information can be found alongside the online version of this article at www.erj.ersjournals.com

\section{REFERENCES}

1 Bauer TT, Ewig S, Marre R, et al. CRB-65 predicts death from community-acquired pneumonia. J Intern Med 2006; 260: 93-101.

2 Ewig S, Birkner N, Strauss R, et al. New perspectives on community-acquired pneumonia in 388,406 patients. Results from a nationwide mandatory performance measurement programme in healthcare quality. Thorax 2009; 64: 1062-1069.

3 Ewig S, Torres A. Community-acquired pneumonia as an emergency: time for an aggressive intervention to lower mortality. Eur Respir J 2011; 38: 253-260.

4 Carr GE, Yuen TC, McConville JF, et al. Early cardiac arrest in patients hospitalized with pneumonia: a report from the American Heart Association's Get With the Guidelines Resuscitation Program. Chest 2012; 141: 1528-1536.

5 Aliberti S, Amir A, Peyrani P, et al. Incidence, etiology, timing, and risk factors for clinical failure in hospitalized patients with community-acquired pneumonia. Chest 2008; 134: 955-962.

6 Phua J, Ngerng WJ, Lim TK. The impact of a delay in intensive care unit admission for community-acquired pneumonia. Eur Respir J 2010; 36: 826-833.

7 Renaud B, Santin A, Coma E, et al. Association between timing of intensive care unit admission and outcomes for emergency 
department patients with community-acquired pneumonia. Crit Care Med 2009; 37: 2867-2874.

8 Restrepo MI, Mortensen EM, Rello J, et al. Late admission to the ICU in patients with community-acquired pneumonia is associated with higher mortality. Chest 2010; 137: 552-557.

9 Dellinger RP, Levy MM, Carlet JM, et al. Surviving Sepsis Campaign: international guidelines for management of severe sepsis and septic shock: 2008. Crit Care Med 2008; 36: 296-327.

10 Kumar A, Roberts D, Wood KE, et al. Duration of hypotension before initiation of effective antimicrobial therapy is the critical determinant of survival in human septic shock. Crit Care Med 2006; 34: 1589-1596.

11 Puskarich MA, Trzeciak S, Shapiro NI, et al. Association between timing of antibiotic administration and mortality from septic shock in patients treated with a quantitative resuscitation protocol. Crit Care Med 2011; 39: 2066-2071.

12 Ewig S, Klapdor B, Pletz MW, et al. Nursing-home-acquired pneumonia in Germany: an 8-year prospective multicentre study. Thorax 2012; 67: 132-138.

13 Fine MJ, Auble TE, Yealy DM, et al. A prediction rule to identify low-risk patients with community-acquired pneumonia. $N$ Engl J Med 1997; 336: 243-250.

14 Corrales-Medina VF, Musher DM, Wells GA, et al. Cardiac complications in patients with community-acquired pneumonia: incidence, timing, risk factors, and association with short-term mortality. Circulation 2012; 125: 773-781.

15 Lim WS, van der Eerden MM, Laing $\mathrm{R}$, et al. Defining community acquired pneumonia severity on presentation to hospital: an international derivation and validation study. Thorax 2003; 58: 377-382.

16 Ewig S, Welte T. CRB-65 for the assessment of pneumonia severity: who could ask for more? Thorax 2008; 63: 665-666.

17 Woodhead M, Blasi F, Ewig S, et al. Guidelines for the management of adult lower respiratory tract infections-full version. Clin Microbiol Infect 2011; 17: Suppl. 6, E1-E59.

18 Loke YK, Kwok CS, Niruban A, et al. Value of severity scales in predicting mortality from community-acquired pneumonia: systematic review and meta-analysis. Thorax 2010; 65: 884-890.

19 Chalmers JD, Singanayagam A, Akram AR, et al. Severity assessment tools for predicting mortality in hospitalised patients with community-acquired pneumonia. Systematic review and meta-analysis. Thorax 2010; 65: 878-883.

20 Ewig S, Ruiz M, Mensa J, et al. Severe community-acquired pneumonia: assessment of severity criteria. Am J Respir Crit Care Med 1998; 158: 1102-1108.

21 Mandell LA, Wunderink RG, Anzueto A, et al. Infectious Diseases Society of America/American Thoracic Society Consensus Guidelines on the Management of CommunityAcquired Pneumonia in Adults. Clin Infect Dis 2007; 44: Suppl. 2, S27-S72.

22 Chalmers JD, Mandal P, Singanayagam A, et al. Severity assessment tools to guide ICU admission in communityacquired pneumonia: systematic review and meta-analysis. Intensive Care Med 2011; 37: 1409-1420.

23 Chalmers JD, Taylor JK, Mandal $\mathrm{P}$, et al. Validation of the Infectious Diseases Society of America/American Thoratic Society minor criteria for intensive care unit admission in community-acquired pneumonia patients without major criteria or contraindications to intensive care unit care. Clin Infect Dis 2011; 53: 503-511.

24 Charles PG, Wolfe R, Whitby M, et al. SMART-COP: a tool for predicting the need for intensive respiratory or vasopressor support in community-acquired pneumonia. Clin Infect Dis 2008; 47: 375-384.

25 Espana PP, Capelastegui A, Gorordo I, et al. Development and validation of a clinical prediction rule for severe communityacquired pneumonia. Am J Respir Crit Care Med 2006; 174: 1249-1256.
26 Yandiola PP, Capelastegui A, Quintana J, et al. Prospective comparison of severity scores for predicting clinically relevant outcomes for patients hospitalized with community-acquired pneumonia. Chest 2009; 135: 1572-1579.

27 Buising KL, Thursky KA, Black JF, et al. Identifying severe community-acquired pneumonia in the emergency department: a simple clinical prediction tool. Emerg Med Australas 2007; 19: 418-426.

28 Renaud B, Labarere J, Coma E, et al. Risk stratification of early admission to the intensive care unit of patients with no major criteria of severe community-acquired pneumonia: development of an international prediction rule. Crit Care 2009; 13: R54.

29 Ewig S, Woodhead M, Torres A. Towards a sensible comprehension of severe community-acquired pneumonia. Intensive Care Med 2011; 37: 214-223.

30 Marrie TJ, Lau CY, Wheeler SL, et al. A controlled trial of a critical pathway for treatment of community-acquired pneumonia. CAPITAL Study Investigators. Community-Acquired Pneumonia Intervention Trial Assessing Levofloxacin. JAMA 2000; 283: 749-755.

31 Carratala J, Fernandez-Sabe N, Ortega L, et al. Outpatient care compared with hospitalization for community-acquired pneumonia: a randomized trial in low-risk patients. Ann Intern Med 2005; 142: 165-172.

32 Atlas SJ, Benzer TI, Borowsky LH, et al. Safely increasing the proportion of patients with community-acquired pneumonia treated as outpatients: an interventional trial. Arch Intern Med 1998; 158: 1350-1356.

33 Renaud B, Coma E, Labarere J, et al. Routine use of the Pneumonia Severity Index for guiding the site-of-treatment decision of patients with pneumonia in the emergency department: a multicenter, prospective, observational, controlled cohort study. Clin Infect Dis 2007; 44: 41-49.

34 Buising KL, Thursky KA, Black JF, et al. A prospective comparison of severity scores for identifying patients with severe community acquired pneumonia: reconsidering what is meant by severe pneumonia. Thorax 2006; 61: 419-424.

35 Chalmers JD, Singanayagam A, Hill AT. Predicting the need for mechanical ventilation and/or inotropic support for young adults admitted to the hospital with community-acquired pneumonia. Clin Infect Dis 2008; 47: 1571-1574.

36 Deeks JJ, Altman DG. Diagnostic tests 4: likelihood ratios. BMJ 2004; 329: 168-169.

37 Kothe H, Bauer T, Marre R, et al. Outcome of communityacquired pneumonia: influence of age, residence status and antimicrobial treatment. Eur Respir J 2008; 32: 139-146.

38 Akram AR, Singanayagam A, Choudhury G, et al. Incidence and prognostic implications of acute kidney injury on admission in patients with community-acquired pneumonia. Chest 2010; 138: 825-832.

39 Yende S, van der PT, Lee $\mathrm{M}$, et al. The influence of pre-existing diabetes mellitus on the host immune response and outcome of pneumonia: analysis of two multicentre cohort studies. Thorax 2010; 65: 870-877.

40 Viasus D, Garcia-Vidal C, Castellote J, et al. Communityacquired pneumonia in patients with liver cirrhosis: clinical features, outcomes, and usefulness of severity scores. Medicine (Baltimore) 2011; 90: 110-118.

41 Dremsizov T, Clermont G, Kellum JA, et al. Severe sepsis in community-acquired pneumonia: when does it happen, and do systemic inflammatory response syndrome criteria help predict course? Chest 2006; 129: 968-978.

42 American Thoracic Society. Infectious Diseases Society of America. Guidelines for the Management of Adults with Hospital-acquired, Ventilator-associated, and Healthcare-associated Pneumonia. Am J Respir Crit Care Med 2005; 171: 388-416. 
43 Ewig S, Welte T, Chastre J, et al. Rethinking the concepts of community-acquired and health-care-associated pneumonia. Lancet Infect Dis 2010; 10: 279-287.

44 Polverino E, Dambrava P, Cilloniz C, et al. Nursing homeacquired pneumonia: a 10 year single-centre experience. Thorax 2010; 65: 354-359.

45 Garcia-Vidal C, Viasus D, Roset A, et al. Low incidence of multidrug-resistant organisms in patients with healthcareassociated pneumonia requiring hospitalization. Clin Microbiol Infect 2011; 17: 1659-1665.

46 Chalmers JD, Taylor JK, Singanayagam A, et al. Epidemiology, antibiotic therapy, and clinical outcomes in health care-associated pneumonia: a UK cohort study. Clin Infect Dis 2011; 53: 107-113.

47 Naito T, Suda T, Yasuda K, et al. A validation and potential modification of the pneumonia severity index in elderly patients with community-acquired pneumonia. J Am Geriatr Soc 2006; 54 $1212-1219$.

48 Torres $\mathrm{OH}, \mathrm{Munoz} J$, Ruiz D, et al. Outcome predictors of pneumonia in elderly patients: importance of functional assessment. J Am Geriatr Soc 2004; 52: 1603-1609.

49 El-Solh AA, Alhajhusain A, Abou JP, et al. Validity of severity scores in hospitalized patients with nursing home-acquired pneumonia. Chest 2010; 138: 1371-1376.

50 Ewig S, Bauer T, Richter K, et al. Prediction of in-hospital death from community-acquired pneumonia by varying CRB-age groups. Eur Respir J 2012 [in press DOI: 10.1183/09031936. 00065212]

51 Halm EA, Fine MJ, Marrie TJ, et al. Time to clinical stability in patients hospitalized with community-acquired pneumonia: implications for practice guidelines. JAMA 1998; 279: 1452-1457.

52 Menendez R, Martinez R, Reyes S, et al. Stability in communityacquired pneumonia: one step forward with markers? Thorax 2009; 64: 987-992.

53 Halm EA, Fine MJ, Kapoor WN, et al. Instability on hospital discharge and the risk of adverse outcomes in patients with pneumonia. Arch Intern Med 2002; 162: 1278-1284.

54 Oosterheert JJ, Bonten MJ, Schneider MM, et al. Effectiveness of early switch from intravenous to oral antibiotics in severe community acquired pneumonia: multicentre randomised trial. BMJ 2006; 333: 1193-1197.

55 El Moussaoui R, de Borgie CA, van den BP, et al. Effectiveness of discontinuing antibiotic treatment after three days versus eight days in mild to moderate-severe community acquired pneumonia: randomised, double blind study. BMJ 2006; 332: 1355-1360.

56 Menendez R, Martinez R, Reyes S, et al. Biomarkers improve mortality prediction by prognostic scales in community-acquired pneumonia. Thorax 2009; 64: 587-591.

57 Chalmers JD, Singanayagam A, Hill AT. C-reactive protein is an independent predictor of severity in community-acquired pneumonia. Am J Med 2008; 121: 219-225.

58 Kruger S, Ewig S, Marre R, et al. Procalcitonin predicts patients at low risk of death from community-acquired pneumonia across all CRB-65 classes. Eur Respir J 2008; 31: 349-355.

59 Huang DT, Weissfeld LA, Kellum JA, et al. Risk prediction with procalcitonin and clinical rules in community-acquired pneumonia. Ann Emerg Med 2008; 52: 48-58.

60 Ramirez P, Ferrer M, Marti V, et al. Inflammatory biomarkers and prediction for intensive care unit admission in severe communityacquired pneumonia. Crit Care Med 2011; 39: 2211-2217.

61 Kolditz M, Halank M, Schulte-Hubbert B, et al. Adrenal function is related to prognosis in moderate community-acquired pneumonia. Eur Respir J 2010; 36: 615-621.

62 Charles PE, Tinel C, Barbar S, et al. Procalcitonin kinetics within the first days of sepsis: relationship with the appropriateness of antibiotic therapy and the outcome. Crit Care 2009; 13: R38.
63 Boussekey N, Leroy O, Alfandari S, et al. Procalcitonin kinetics in the prognosis of severe community-acquired pneumonia. Intensive Care Med 2006; 32: 469-472.

64 Bruns AH, Oosterheert JJ, Hak E, et al. Usefulness of consecutive C-reactive protein measurements in follow-up of severe community-acquired pneumonia. Eur Respir J 2008; 32: 726-732.

65 Coelho L, Povoa P, Almeida E, et al. Usefulness of C-reactive protein in monitoring the severe community-acquired pneumonia clinical course. Crit Care 2007; 11: R92-R100.

66 Kolditz M, Halank M, Schulte-Hubbert B, et al. Procalcitonin improves the differentiation between infectious and cryptogenic/ secondary organizing pneumonia. J Infect 2012; 64: 122-124.

67 Christ-Crain M, Stolz D, Bingisser R, et al. Procalcitonin guidance of antibiotic therapy in community-acquired pneumonia: a randomized trial. Am J Respir Crit Care Med 2006; 174: 84-93.

68 Bouadma L, Luyt CE, Tubach F, et al. Use of procalcitonin to reduce patients' exposure to antibiotics in intensive care units (PRORATA trial): a multicentre randomised controlled trial. Lancet 2010; 375: 463-474.

69 Schuetz P, Chiappa V, Briel M, et al. Procalcitonin algorithms for antibiotic therapy decisions: a systematic review of randomized controlled trials and recommendations for clinical algorithms. Arch Intern Med 2011; 171: 1322-1331.

70 Hoffken G, Lorenz J, Kern W, et al. Epidemiologie, diagnostik, antimikrobielle therapie und management von erwachsenen patienten mit ambulant erworbenen unteren atemwegsinfektionen sowie ambulant erworbener pneumonie - Update 2009. S3 Leitlinie der Paul-Ehrlich-Gesellschaft für Chemotherapie, der Deutschen Gesellschaft für Pneumologie und Beatmungsmedizin, der Deutschen Gesellschaft für Infektiologie und vom Kompetenznetzwerk CAPNETZ. [Epidemiology, diagnosis, antimicrobial therapy and management of community-acquired pneumonia and lower respiratory tract infections in adults. Guidelines of the Paul-Ehrlich-Society for Chemotherapy, the German Respiratory Society, the German Society for Infectiology and the Competence Network CAPNETZ Germany.] Pneumologie 2009; 63: e1-e68.

71 Koeze J, Hendrix MG, van den Bergh FA, et al. In critically ill patients the procalcitonin level can be misleading. Crit Care 2011; 15: 422 .

72 Kruger S, Ewig S, Papassotiriou J, et al. Inflammatory parameters predict etiologic patterns but do not allow for individual prediction of etiology in patients with CAP: results from the German competence network CAPNETZ. Respir Res 2009; 10: 65.

73 Schuetz P, Suter-Widmer I, Chaudri A, et al. Prognostic value of procalcitonin in community-acquired pneumonia. Eur Respir J 2011; 37: 384-392.

74 Jensen JU, Hein L, Lundgren B, et al. Procalcitonin-guided interventions against infections to increase early appropriate antibiotics and improve survival in the intensive care unit: a randomized trial. Crit Care Med 2011; 39: 2048-2058.

75 Nowak A, Breidthardt T, Christ-Crain M, et al. Direct comparison of three natriuretic peptides for prediction of short- and long-term mortality in patients with community-acquired pneumonia. Chest 2012; 141: 974-982.

76 Schuetz P, Christ-Crain M, Zimmerli W, et al. Repeated measurements of endothelin-1 precursor peptides predict the outcome in community-acquired pneumonia. Intensive Care Med 2011; 37: 970-980.

77 Kruger S, Ewig S, Giersdorf S, et al. Cardiovascular and inflammatory biomarkers to predict short- and long-term survival in community-acquired pneumonia: results from the German Competence Network, CAPNETZ. Am J Respir Crit Care Med 2010; 182: 1426-1434.

78 Schuetz P, Wolbers M, Christ-Crain M, et al. Prohormones for prediction of adverse medical outcome in community-acquired 
pneumonia and lower respiratory tract infections. Crit Care 2010; 14: R106.

79 Kruger S, Ewig S, Kunde J, et al. Pro-atrial natriuretic peptide and pro-vasopressin for predicting short-term and long-term survival in community-acquired pneumonia: results from the German Competence Network CAPNETZ. Thorax 2010; 65: 208-214.

80 Muller B, Morgenthaler N, Stolz D, et al. Circulating levels of copeptin, a novel biomarker, in lower respiratory tract infections. Eur J Clin Invest 2007; 37: 145-152.

81 Kruger S, Papassotiriou J, Marre R, et al. Pro-atrial natriuretic peptide and pro-vasopressin to predict severity and prognosis in community-acquired pneumonia: results from the German competence network CAPNETZ. Intensive Care Med 2007; 33: 2069-2078.

82 Masia M, Papassotiriou J, Morgenthaler NG, et al. Midregional pro-A-type natriuretic peptide and carboxy-terminal provasopressin may predict prognosis in community-acquired pneumonia. Clin Chem 2007; 53: 2193-2201.

83 Kruger S, Ewig S, Kunde J, et al. C-terminal provasopressin (copeptin) in patients with community-acquired pneumoniainfluence of antibiotic pre-treatment: results from the German competence network CAPNETZ. J Antimicrob Chemother 2009; 64: 159-162.

84 Kolditz M, Halank M, Schulte-Hubbert B, et al. Copeptin predicts clinical deterioration and persistent instability in communityacquired pneumonia. Respir Med 2012; 106: 1320-1328.

85 Christ-Crain M, Morgenthaler NG, Stolz D, et al. Pro-adrenomedullin to predict severity and outcome in community-acquired pneumonia [ISRCTN04176397]. Crit Care 2006; 10: R96.

86 Huang DT, Angus DC, Kellum JA, et al. Midregional proadrenomedullin as a prognostic tool in community-acquired pneumonia. Chest 2009; 136: 823-831.

87 Albrich WC, Dusemund F, Ruegger K, et al. Enhancement of CURB65 score with proadrenomedullin (CURB65-A) for outcome prediction in lower respiratory tract infections: derivation of a clinical algorithm. BMC Infect Dis 2011; 11: 112.

88 Guertler C, Wirz B, Christ-Crain M, et al. Inflammatory responses predict long-term mortality risk in communityacquired pneumonia. Eur Respir J 2011; 37: 1439-1446.

89 Bello S, Lasierra AB, Minchole E, et al. Prognostic power of proadrenomedullin in community-acquired pneumonia is independent of aetiology. Eur Respir J 2012; 39: 1144-1155.
90 Suberviola B, Castellanos-Ortega A, Llorca J, et al. Prognostic value of proadrenomedullin in severe sepsis and septic shock patients with community-acquired pneumonia. Swiss Med Wkly 2012; 142: w13542.

91 Renaud B, Schuetz P, Claessens YE, et al. Proadrenomedullin improves REA-ICU score for predicting Early Severe Community-Acquired Pneumonia. Chest 2012; 142: 1447-1454.

92 Querol-Ribelles JM, Tenias JM, Grau E, et al. Plasma D-dimer levels correlate with outcomes in patients with communityacquired pneumonia. Chest 2004; 126: 1087-1092.

93 Chalmers JD, Singanayagam A, Scally C, et al. Admission Ddimer can identify low-risk patients with community-acquired pneumonia. Ann Emerg Med 2009; 53: 633-638.

94 Mirsaeidi M, Peyrani P, Aliberti S, et al. Thrombocytopenia and thrombocytosis at time of hospitalization predict mortality in patients with community-acquired pneumonia. Chest 2010; 137: 416-420.

95 Christ-Crain M, Stolz D, Jutla S, et al. Free and total cortisol levels as predictors of severity and outcome in community-acquired pneumonia. Am J Respir Crit Care Med 2007; 176: 913-920.

96 Gotoh S, Nishimura N, Takahashi O, et al. Adrenal function in patients with community-acquired pneumonia. Eur Respir J 2008; 31: 1268-1273.

97 Salluh JI, Bozza FA, Soares M, et al. Adrenal response in severe community-acquired pneumonia: impact on outcomes and disease severity. Chest 2008; 134: 947-954.

98 Remmelts HH, Meijvis SC, Kovaleva A, et al. Changes in serum cortisol levels during community-acquired pneumonia: the influence of dexamethasone. Respir Med 2012; 106: 905-908.

99 Kolditz M, Hoffken G, Martus P, et al. Serum cortisol predicts death and critical disease independently of CRB-65 score in community-acquired pneumonia: a prospective observational cohort study. BMC Infect Dis 2012; 12: 90.

100 Cooper MS, Stewart PM. Corticosteroid insufficiency in acutely ill patients. New Eng J Med 2003; 348: 727-734.

101 Arafah BM. Hypothalamic pituitary adrenal function during critical illness: limitations of current assessment methods. J Clin Endocrinol Metab 2006; 91: 3725-3745.

102 Katan M, Christ-Crain M. The stress hormone copeptin: a new prognostic biomarker in acute illness. Swiss Med Wkly 2010; 140: w13101.

103 Van den Berghe G, de Zegher F, Bouillon R. Clinical review 95: acute and prolonged critical illness as different neuroendocrine paradigms. J Clin Endocrinol Metab 1998; 83: 1827-1834. 